\title{
Effect of Steatite Waste Additions on the Physical and Mechanical Properties of Clay Composites
}

Túlio Hallak Panzera ${ }^{\mathrm{a},}$, Kurt Strecker ${ }^{\mathrm{a}}$, Luiddimar Geraldo de Oliveira ${ }^{\mathrm{a}}$,

Wander Luiz Vasconcelos ${ }^{\mathrm{b}}$, Marco Antônio Schiavon ${ }^{\mathrm{c}}$

${ }^{a}$ Department of Mechanical Engineering, Federal University of São João del-Rei - UFSJ, Campus Sto Antônio, Praça Frei Orlando 170, CEP 36307-352, São João del-Rei, MG, Brazil

${ }^{\mathrm{b}}$ Department of Metallurgical and Materials Engineering, Federal University of Minas Gerais - UFMG, CEP 31270-901, Belo Horizonte, MG, Brazil

${ }^{\circ}$ Department of Natural Sciences, Federal University of São João del-Rei - UFSJ, Campus Sto Antônio, Praça Frei Orlando 170, CEP 36307-352, São João del-Rei, MG, Brazil

Received: September 22, 2010

\begin{abstract}
Mineral rock wastes are being widely investigated due to possible damage to the environment when discarded indiscriminately in the nature, but also because of their great potential as ceramic raw materials. This work aims to study the effect of steatite particle additions on the mechanical properties of clay composites. A comprehensive series of experiments have been conducted to assess the influence of: steatite particle size, steatite fraction and compacting pressure on the performance of clay composites. The composite of superior properties was manufactured with $20 \mathrm{wt}$. (\%) of steatite, 100-200 US-Tyler of steatite particle size and $30 \mathrm{MPa}$ of compacting pressure.
\end{abstract}

Keywords: steatite, clay, composites, mechanical properties

\section{Introduction}

In recent years, the investigation of industrial wastes for use as alternative materials has been intensified across the world. The raw materials used in the traditional ceramic industry generally are constituted of plastic and non-plastic materials, of varied compositions, reason which allows the presence of many residual substances ${ }^{1}$.

The main industrial wastes used as dispersive phase in ceramic composites are commonly from: the mining ${ }^{2-6}$, the ceramic industry ${ }^{7}$, the steel mill ${ }^{8-9}$ and the energy industries ${ }^{10-11}$, besides other urban residues ${ }^{12}$ which can be incorporated after adequate treatment.

Mineral rock wastes are widely studied due to the great environmental impact when discarded indiscriminately in the nature and also to their huge potential as ceramic raw materials ${ }^{13}$.

The steatite mineral, commonly known as soapstone, is the name given to a metamorphic rock, basically composed of talc and many other minerals such as magnetite and silica ${ }^{14-15}$. Talc is a hydrated magnesium silicate, with the following chemical formulation: $\mathrm{Mg}_{3} \mathrm{Si}_{4} \mathrm{O}_{10}(\mathrm{OH})_{2}^{[16]}$.

The effect of steatite additions in clay composites was investigated in this work. A full factorial Design of Experiment (DOE) was adopted in order to identify the main and the interaction effects of the factors compacting pressure, weight fraction and particle size of the steatite waste, on the responses, such as: linear shrinkage, apparent density, apparent porosity and flexural strength.

\section{Materials and Methods}

The ceramic composites were constituted of two phases, the clay matrix phase and the steatite waste powders used as dispersive phase.

\subsection{Matrix phase: São Simão clay}

A chemical analysis by X-ray fluorescence was conducted to characterize the São Simão clay. The results are shown in Table 1, where a high percentage of silicon oxide $(48.90 \%)$ and aluminium oxide (36.30\%) were identified. The apparent density of $1.31 \mathrm{~g} . \mathrm{cm}^{-3}$ was obtained by nitrogen gas picnometry technique.

\subsection{Dispersive phase: steatite waste}

The mineral wastes of steatite were collected in the city of Congonhas (Minas Gerais, Brazil). The powder of steatite was dried in an oven at $80{ }^{\circ} \mathrm{C}$ for 24 hours and classified by sieving in two particle size envelopes: 16-40 and 100-200 US-Tyler. Table 2 shows the chemical analysis of the steatite material obtained by $\mathrm{X}$-ray fluorescence spectroscopy, identifying high contents of silicon oxide $(44.73 \%)$ and magnesium oxide $(29.28 \%)$, as expected for a magnesium silicate. The apparent density $\left(0.76 \mathrm{~g} . \mathrm{cm}^{-3}\right)$ of steatite particles was determined by nitrogen gas picnometry technique.

\subsection{Full factorial planning}

The full factorial planning of type $\mathrm{n}^{\mathrm{k}}$ consists of investigating all possible combinations of the experimental factors $(\mathrm{k})$ and its respective levels (n). The result of the factorial $\mathrm{n}^{\mathrm{k}}$ corresponds to the number of the experimental conditions existent in the experiment ${ }^{17-18}$.

The chosen responses in this experiment and their respective standards were: linear shrinkage ${ }^{19}$, apparent density ${ }^{20}$, apparent porosity $^{21}$ and flexural strength ${ }^{22}$. Two qualitative experiments were performed for the microstructural analysis, that is, X-ray diffraction analysis (XRD) and backscatter scanning electron microscopy (SEM).

Three experimental factors were investigated with their respective levels: the weight fractions of the steatite phase (5, 20 and 40\%), the steatite particle size envelopes (16-40 and 100-200 US-Tyler) and the compacting pressures (10 and $30 \mathrm{MPa})$. Some factors were kept constant in the experiment such as: the water content (6 wt. (\%)), the time of mixture (5 minutes) and the environmental temperature of manufacture $\left(\sim 22^{\circ} \mathrm{C}\right)$. Table 3 shows the experimental factors and the 
levels which were investigated in this work, establishing a factorial planning matrix of type $3^{1} 2^{1} 2^{1}$ that provide 12 distinct experimental combinations.

The statistical techniques Design of Experiment (DOE) and the Analysis of Variance (ANOVA) provided the significance of each factor on the investigated responses. The statistical software, Minitab v.14 was used to perform the mathematical planning and the data analysis.

Table 1. Chemical analysis of São Simão clay.

\begin{tabular}{cc}
\hline Chemical element & Results $(\%)$ \\
\hline $\mathrm{SiO}_{2}$ & 48.90 \\
$\mathrm{Al}_{2} \mathrm{O}_{3}$ & 36.30 \\
$\mathrm{Fe}_{2} \mathrm{O}_{3}$ & 1.09 \\
$\mathrm{TiO}_{2}$ & 0.46 \\
$\mathrm{CaO}$ & - \\
$\mathrm{MgO}$ & - \\
$\mathrm{Na}_{2} \mathrm{O}$ & - \\
$\mathrm{K}_{2} \mathrm{O}$ & 0.24 \\
Loss on ignition (LOI) & 13.00 \\
\hline
\end{tabular}

Table 2. Chemical analysis of steatite.

\begin{tabular}{cc}
\hline Chemical element & Results $(\%)$ \\
\hline $\mathrm{SiO}_{2}$ & 44.73 \\
$\mathrm{Al}_{2} \mathrm{O}_{3}$ & 3.70 \\
$\mathrm{Fe}_{2} \mathrm{O}_{3}$ & 8.38 \\
$\mathrm{TiO}_{2}$ & $<0.001$ \\
$\mathrm{CaO}$ & 2.95 \\
$\mathrm{MgO}$ & 29.28 \\
$\mathrm{NaO}_{2}$ & $<0.001$ \\
$\mathrm{~K}_{2} \mathrm{O}$ & $<0.001$ \\
$\mathrm{MnO}$ & 0.13 \\
$\mathrm{P}_{2} \mathrm{O}_{5}$ & 0.01 \\
Loss of ignition (LOI) & 10.34 \\
\hline
\end{tabular}

Table 3. Planning matrix.

\begin{tabular}{lccc}
\hline & $\begin{array}{c}\text { Particle size } \\
\text { (US-Tyler) }\end{array}$ & $\begin{array}{c}\text { Fraction of } \\
\text { steatite }(\%)\end{array}$ & $\begin{array}{c}\text { Pressure of } \\
\text { compaction (MPa) }\end{array}$ \\
\hline C1 & $16-40$ & 5 & 10 \\
C2 & $16-40$ & 5 & 30 \\
C3 & $100-200$ & 5 & 10 \\
C4 & $100-200$ & 5 & 30 \\
C5 & $16-40$ & 20 & 10 \\
C6 & $16-40$ & 20 & 30 \\
C7 & $100-200$ & 20 & 10 \\
C8 & $100-200$ & 20 & 30 \\
C9 & $16-40$ & 40 & 10 \\
C10 & $16-40$ & 40 & 30 \\
C11 & $100-200$ & 40 & 10 \\
C12 & $100-200$ & 40 & 30 \\
\hline
\end{tabular}

\subsection{Manufacturing process}

The material's preparation and the procedures of curing followed the recommendations of the British Standard (BS12390-2) ${ }^{[23]}$ in order to assure small variability in the manufacturing process. A randomization procedure was adopted to prepare and carry out the sample tests, allowing an arbitrary ordinance of the experimental conditions, preventing that non-controlled factors affected the responses $^{17-18}$.

A prismatic steel die was used to manufacture the specimens. The ceramic powder was mixed using a constant water percentage of 6 wt. (\%). The ceramic material was leaked and compacted under two pressure levels, 10 and $30 \mathrm{MPa}$, during 30 seconds. The composites were subsequently sintered with a heating rate of $3{ }^{\circ} \mathrm{C} / \mathrm{min}$ up to the temperature of $1200{ }^{\circ} \mathrm{C}$ followed by 40 minutes of isothermal sintering. The dimensions of the prismatic green samples were: $20.5 \times 5 \times 70.6 \mathrm{~mm}$.

Six specimens were manufactured for each experimental condition. Taking into account 12 experimental conditions and 2 replicates, 144 specimens were prepared. The replicate consists of a repetition of the experimental condition in order to provide an estimate of the magnitude of the experimental error against which the differences among the treatments are judged. The extension of this error is important to decide whether significant effects exist or can be attributed to the action of factors ${ }^{17-18}$.

\section{Experimental Results}

Table 4 exhibits the P-values of the Analysis of Variance (ANOVA) for the mean of the responses. The P-values indicate which of the effects in the system are statistically significant, based on the examination of the experimental data from replicate 1 and replicate 2 . If the P-value is less than or equal to 0.05 the effect is considered to be significant. A $\alpha$-level of 0.05 is the level of significance which implies that there is $95 \%$ probability of the effect being significant. The results will be presented via 'main effect' and 'interaction' plots. These graphic plots cannot be considered typical 'scatter' plots, but serve to illustrate the statistical analysis and provide the variation on the significant effects. The main effect of a factor only must be interpreted individually if there is no evidence that it does not interact with other factors. When one or more interaction effect of superior order is significant, the factors that interact must be considered jointly ${ }^{17-18}$.

The 'main effects' plot is most useful when several factors such as particle size, weight fraction and compacting pressure affect the composite property. These plots are used to compare the changes in the mean level to examine which of the processing factors influences the response (e.g. apparent density) the most. A 'main effect' is present when different levels of a factor affect the response differently.

An 'interaction' is present when the change in the mean response of the composite (e.g. apparent density) from a low to high level of a factor (e.g. particle size) depends on the level of a second factor (e.g. weight fraction $)^{17}$. Interactions plots are used to visualize the interaction effect of two or more factors (e.g. size and geometry; size and pressure; geometry and pressure; size, geometry and pressure) on the response and to compare the relative strength of the effects.

The value of ' $\mathrm{R}^{2}$ adjust' shown in the ANOVA analysis indicates how well the model predicts responses for new observations. Larger values of adjusted $R^{2}(\mathrm{adj})$ suggest models of greater predictive ability ${ }^{17-18}$. Table 4 shows the values of $R^{2}(\operatorname{adj})$ for the responses. A variation from 85.70 to $95.10 \%$ can be observed, which demonstrate the quality of adjustment of the models being satisfactory.

The 'residuals plots' can be useful for comparing the plots to determine whether your model meets the assumptions of the analysis. 
Table 4. Analysis of variance (P-values).

\begin{tabular}{|c|c|c|c|c|c|}
\hline & Experimental factors & $\begin{array}{c}\text { Linear shrinkage } \\
(\%)\end{array}$ & $\begin{array}{c}\text { Apparent porosity } \\
(\%)\end{array}$ & $\begin{array}{l}\text { Apparent density } \\
\left(\mathrm{g} \cdot \mathrm{cm}^{-3}\right)\end{array}$ & $\begin{array}{l}\text { Flexural strength } \\
\qquad(\mathrm{MPa})\end{array}$ \\
\hline \multirow{3}{*}{$\begin{array}{l}\text { Main } \\
\text { effects }\end{array}$} & Fraction of steatite & 0.000 & 0.428 & $\underline{0.040}$ & 0.000 \\
\hline & Particle size & 0.951 & 0.135 & 0.878 & 0.000 \\
\hline & Compaction & 0.247 & 0.000 & $\underline{0.000}$ & 0.000 \\
\hline \multirow{5}{*}{$\begin{array}{l}\text { Interaction } \\
\text { effects }\end{array}$} & Fraction of steatite $*$ Particle size & 0.098 & 0.066 & 0.351 & $\underline{0.000}$ \\
\hline & Fraction of steatite $*$ Compaction & $\underline{0.017}$ & $\underline{0.004}$ & 0.063 & $\underline{0.004}$ \\
\hline & Particle size $*$ Compaction & 0.525 & 0.641 & 0.098 & 0.420 \\
\hline & Fraction of steatite $*$ Particle size $*$ Compaction & 0.872 & 0.742 & 0.261 & 0.474 \\
\hline & $\mathrm{R}^{2}$ (adjust) $\%$ & 85.70 & 90.68 & 85.78 & 95.10 \\
\hline
\end{tabular}

The normal probability plot indicates whether the data are normally distributed, other variables are influencing the response, or outliers exist in the data. The residuals for all responses investigated in this work are normally distributed following a straight line, validating the ANOVA analysis.

\subsection{X-ray diffraction (XRD)}

The X-ray diffraction (XRD) patterns were collected with powder samples with a diffractometer (Shimadzu, model XRD-6000) operating at $40 \mathrm{kV}$ and $30 \mathrm{~mA}$, with a $\mathrm{CuK} \alpha$ radiation $(\lambda=0.15418 \mathrm{~nm})$ as incident beam. Figure 1 exhibits the XRD results for the samples $\mathrm{C} 2$, C3, C4, C8, C11 and C12.

The XRD patterns of the sample set are displayed in Figure 1 with the corresponding assignments, according to the Joint Committee on Powder Diffraction Standards - JCPDS. The peaks in sample C2 were attributed to quartz and mullite crystalline phases. In sample $\mathrm{C} 3$, besides these crystalline phases, the crystallization of cristobalite started, as observed by the appearance of a peak at $\sim 21.9^{\circ}(2 \theta)$. The composites $\mathrm{C} 2, \mathrm{C} 3$ and $\mathrm{C} 4$ were manufactured with $5 \%$ of steatite particles, but with different levels of particle sizes and compaction pressures.

For the following samples a decrease in the relative intensity of the peaks assigned to quartz can be observed and also an increase in the relative intensity of mullite and cristobalite peaks. This behaviour implies that not only the particle size of steatite, but also the compaction pressure affects the formation of mullite and cristobalite phases.

In addition, in the samples $\mathrm{C} 11$ and $\mathrm{C} 12$ cordierite $\left(2 \mathrm{MgO} \cdot 2 \mathrm{Al}_{2} \mathrm{O}_{3}\right)$ has been detected, due to the higher steatite content used. Apparently, cordierite is formed by the reaction of mullite $\left(3 \mathrm{Al}_{2} \mathrm{O}_{3} \cdot \mathrm{SiO}_{2}\right)$ and steatite $\left(3 \mathrm{MgO} .4 \mathrm{SiO}_{2} \cdot \mathrm{H}_{2} 0\right)$. The higher cordierite content observed in sample $\mathrm{C} 12$ in comparison to sample $\mathrm{C} 11$, both prepared with $40 \mathrm{wt}$. (\%) of steatite is attributed to the higher compaction pressure applied in sample $\mathrm{C} 12$, which increases the contact points between particles and thus accelerates the cordierite phase formation.

\subsection{Linear shrinkage}

The linear shrinkage of the clay composites varied from 3.52 to $8.48 \%$. The interaction of the factors 'fraction of steatite and compaction' affected the linear shrinkage response exhibiting a P-value less than 0.05 (Table 4). It is possible to observe in Figure 2 the steatite fractions of 20 and $40 \%$ provided a reduction of the linear shrinkage of the composites. The presence of magnesium oxide $(\mathrm{MgO})$ in the steatite particles increases the thermal shock resistance and diminishes the sintering shrinkage ${ }^{24}$. An increase of the compacting pressure tends to reduce the existing spaces between particles. The enhancement of the particle packing provides the

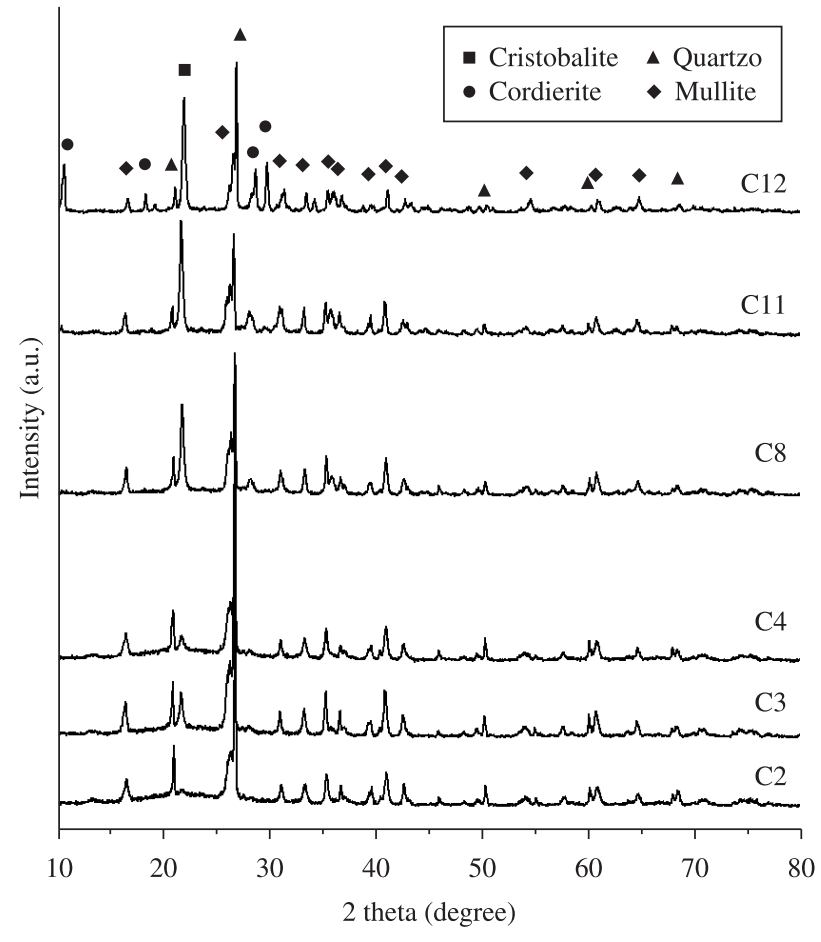

Figure 1. X-ray diffractometer results.

reduction of the atomic diffusion distances, consequently, increasing the linear shrinkage due to liquid phase formation. This phenomenon is more evident when a significant percentage of steatite (20 and $40 \%$ ) is added.

The linear shrinkage of the composites manufactured with 5\% of steatite diminished with the increase of the compacting pressure. This behaviour can be explained by the large particle packing factor obtained in the system, as well as the assumption that the samples have already been close to the final density of the sintered material.

\subsection{Apparent porosity}

The apparent porosity varied from 24.86 to $43.45 \%$. The interaction of second order factors, 'fraction of steatite and compaction', presented a significant effect on the apparent porosity, exhibiting a P-value of 0.004 (Table 4).

A reduction of the apparent porosity as a function of the compaction increase (30 MPa) can be observed in Figure 3. The addition of steatite provided not only the reduction of the linear 
shrinkage, but also the diminishing of the apparent porosity. Studies, carried out by Bajza $^{25}$, showed that an increase in the compacting pressure can be the main reason for the density increase, diminishing the pore diameters and consequently providing high strength of ceramic products.

\subsection{Apparent density}

The apparent density for the composites varied from 1.59 to $2.08 \mathrm{~g} . \mathrm{cm}^{-3}$. The main factors "fraction of steatite" and "pressure of compaction" showed significant effects exhibiting P-values less than 0.05 (Table 4).

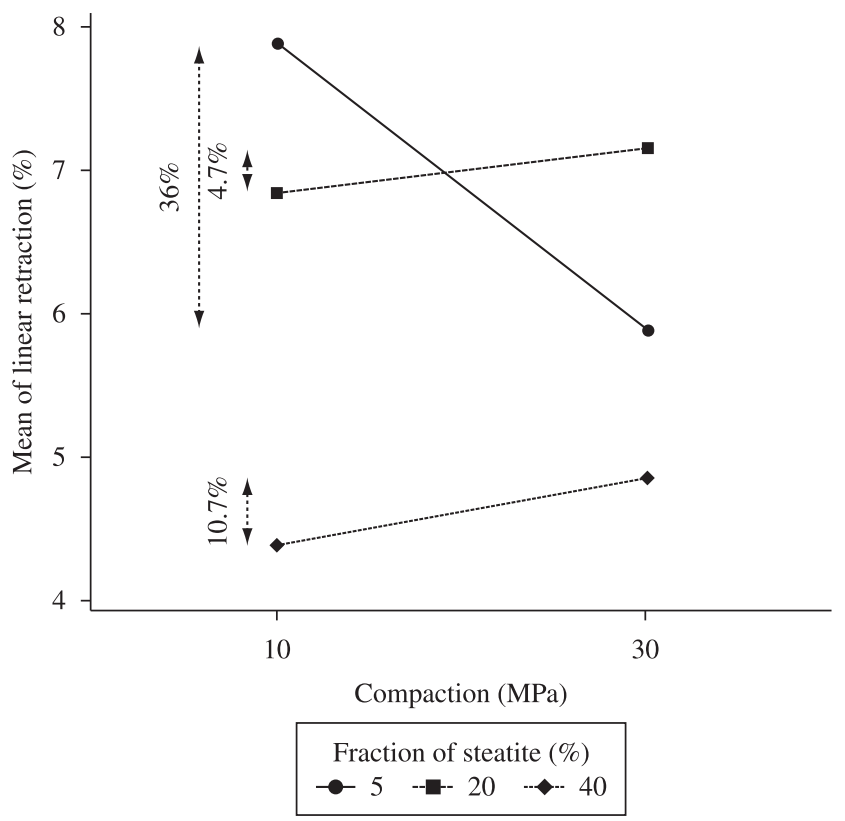

Figure 2. Interaction effect plot for linear shrinkage, fraction of steatite and compaction.

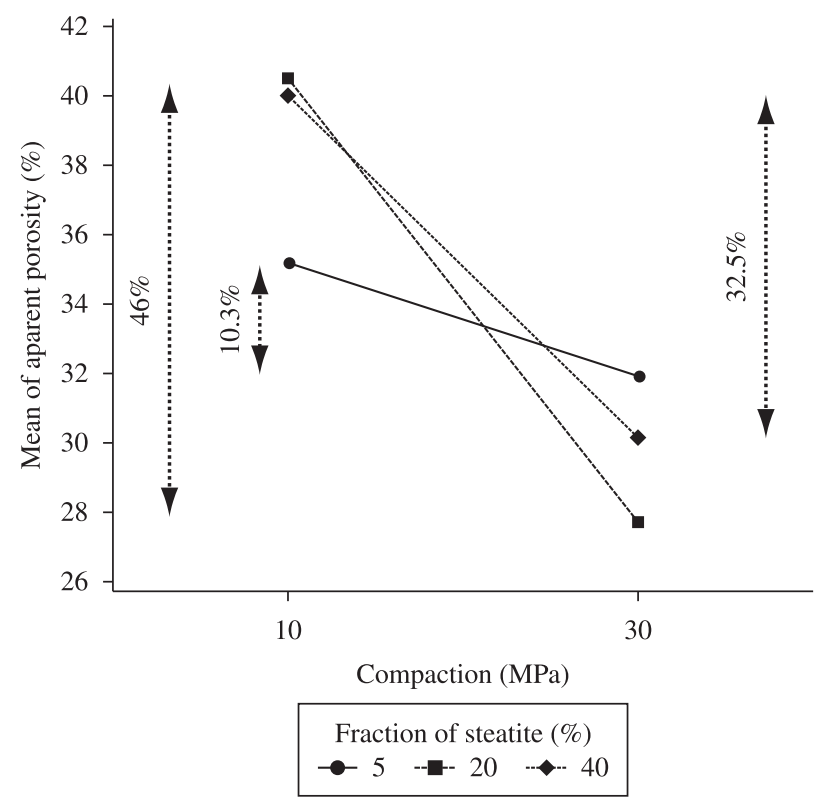

Figure 3. Interaction effect plot for apparent porosity, fraction of steatite and compaction.
Figure $4 \mathrm{a}$ and $4 \mathrm{~b}$ shows the main effects of the factors 'fraction of steatite' and 'compaction' on apparent density, respectively. The change of the fraction levels from 5 to $20 \%$ represents a percentage increase of $4.6 \%$ on the apparent density (Figure 4a). On the other hand, the addition of $40 \%$ of steatite did not provide the same behaviour, which can be explained by the presence of cordierite phase in the materials microstructure. Figure $4 \mathrm{~b}$ shows that the increase of the compacting pressure provides an increase of the apparent density of the composites. The particle packing factor is enhanced with the increase of pressure, consequently increasing the density of the composites.

\subsection{Flexural strength}

The flexural strength varied from 44 to $127 \mathrm{MPa}$. The interactions of second order factors such as 'fraction of steatite and particle size' and 'fraction of steatite and compaction' showed significant effects on the flexural strength response, presenting P-values lesser than 0.05 (Table 4).

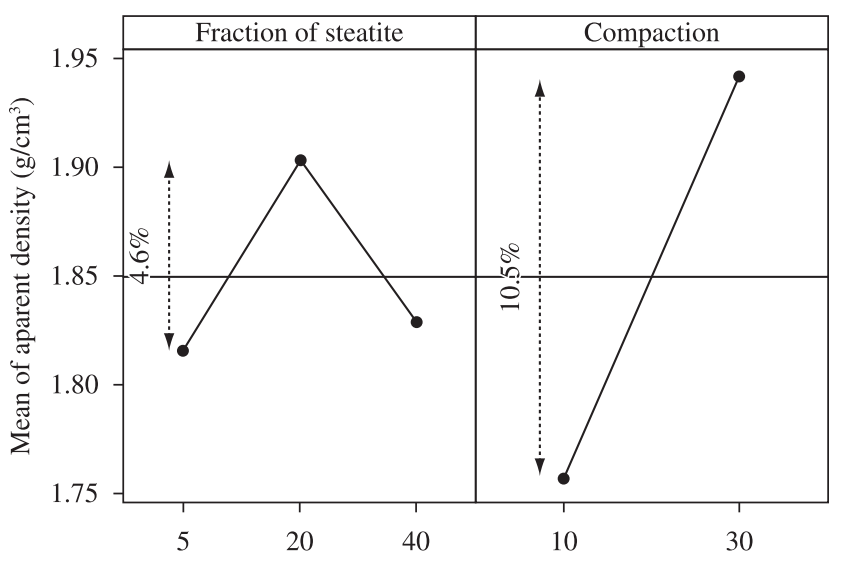

(a)

(b)

Figure 4. Main effect plots for apparent density, fraction of steatite and the compaction.

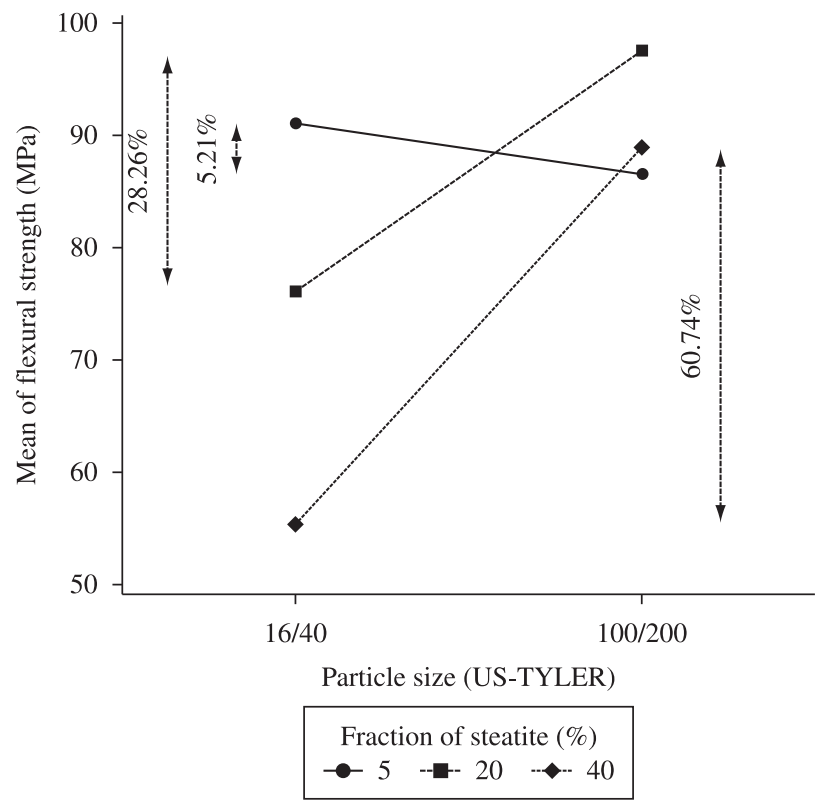

Figure 5. Interaction effect plot for flexural strength, fraction of steatite and particle size. 
The interaction effect plot exhibited in Figure 5 shows that the smaller particles of steatite (100/200 US-Tyler) provided a percentage increase on the flexural strength of 28.26 and $60.47 \%$ for the steatite fractions of 20 and $40 \%$, respectively. However, the same behaviour is not observed for the composite with $5 \%$ of steatite, showing a percentage reduction of $5.21 \%$ when the particle size level is 100-200 US-Tyler. Based on the XRD results, the addition of fine particles of steatite into clay composites contributed to the formation of crystalline phases, i.e, quartz, mullite, cristobalite and cordierite. This behaviour can be attributed to the major particle packing capacity and sintering of grains of smaller diameters, enhancing the mechanical strength of the composites.

The interaction effect plot of Figure 6 exhibits the effect of compacting pressure on the flexural strength response. The strength of the composites is increased when the compacting pressure levels change from 10 to $30 \mathrm{MPa}$. As it was observed in Figure 5, the addition of steatite particles provided an improvement of the mechanical strength of the composites. The steatite fraction of $20 \%$ compacted with $30 \mathrm{MPa}$ exhibited a superior strength. This behaviour is in accordance to the apparent porosity (Figure 3 ) and density (Figure 4a) results, where the composite manufactured with $20 \%$ of steatite showed lower porosity and higher density.

\subsection{Microstructure}

Backscatter-mode scanning electron microscopy (SEM) was used for examination of the composites $\mathrm{C} 3$ and $\mathrm{C} 11$ which correspond to the materials manufactured with 100-200 US-Tyler particle size, $10 \mathrm{MPa}$ of pressure and 5 and $40 \%$ of steatite fraction respectively. Figure 7 and 8 exhibit the images of the composites $\mathrm{C} 3$ and C11, respectively. It is possible to observe that the microstructure of the composite $\mathrm{C} 3$ presents a smaller pore size than $\mathrm{C} 11$. The increase of the steatite fraction with low pressure of compaction (10 MPa) can be the main factor responsible for the increase of the apparent porosity as shown in Figure 3, beyond the decrease of the flexural strength shown in Figure 6.

On the other hand, Figure 9 shows the microstructure of $\mathrm{C} 4$ composite, manufactured with 100-200 US-Tyler particle size, $30 \mathrm{MPa}$ of pressure and $5 \%$ of steatite fraction, exhibiting smaller pore sizes compared to $\mathrm{C} 3$ and $\mathrm{C} 11$, which explains the effect of pressure on the porosity and the mechanical strength of the composites.

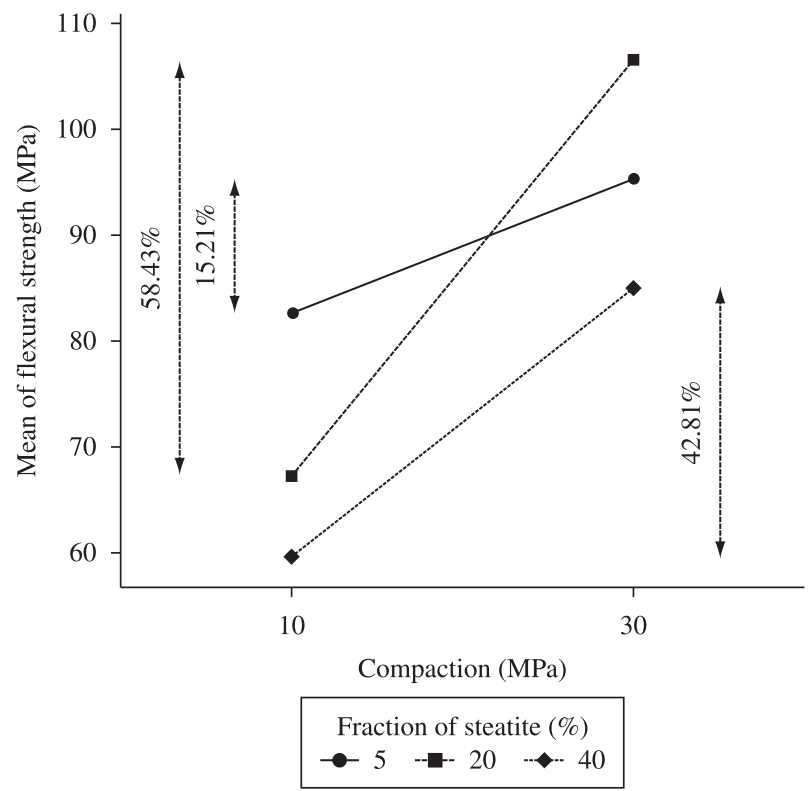

Figure 6. Interaction effect plot for flexural strength, fraction of steatite and compaction.

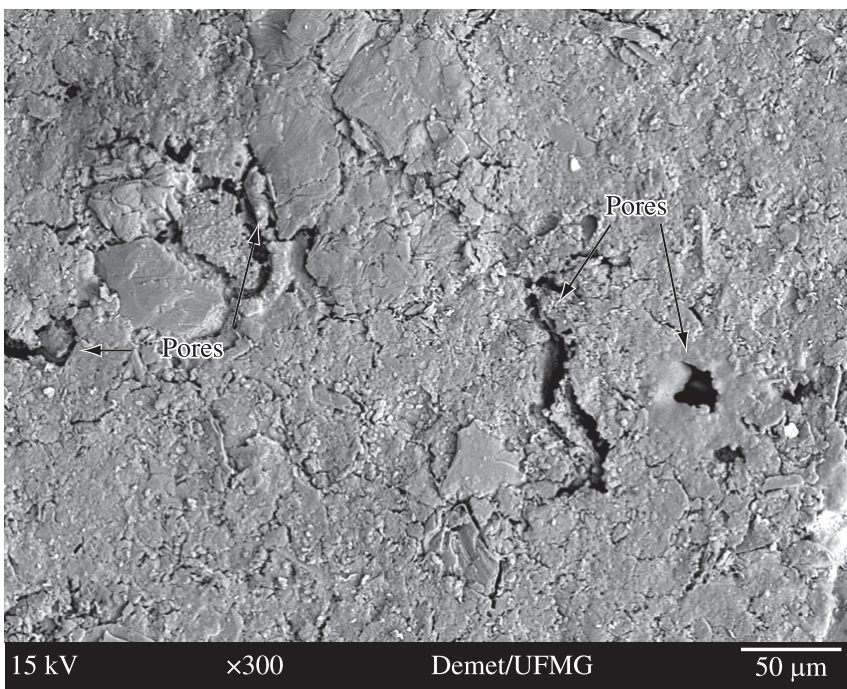

Figure 7. Composite $\mathrm{C} 3$, backscatter-mode scanning electron microscopy image.

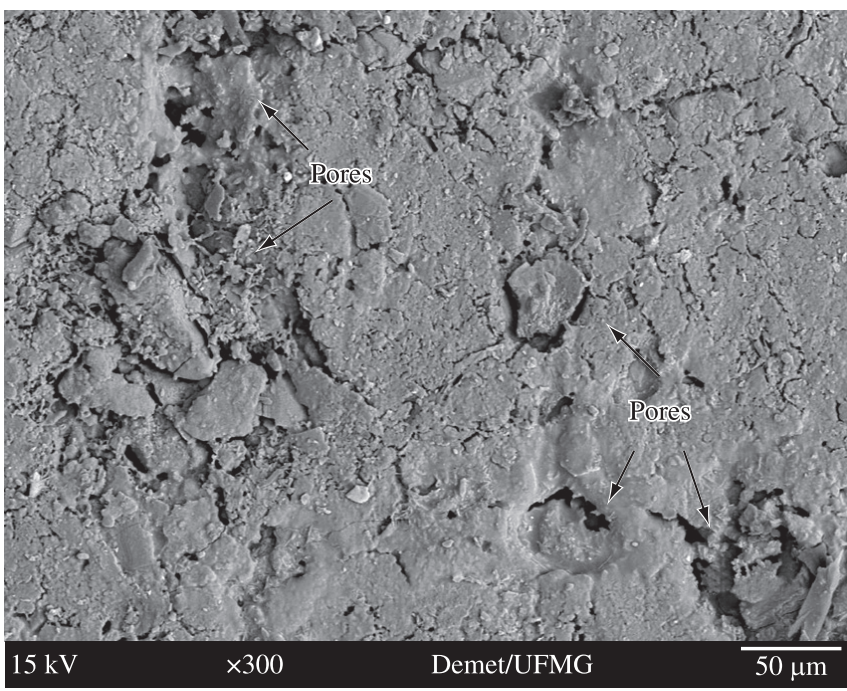

Figure 8. Composite $\mathrm{C} 11$, backscatter-mode scanning electron microscopy image.

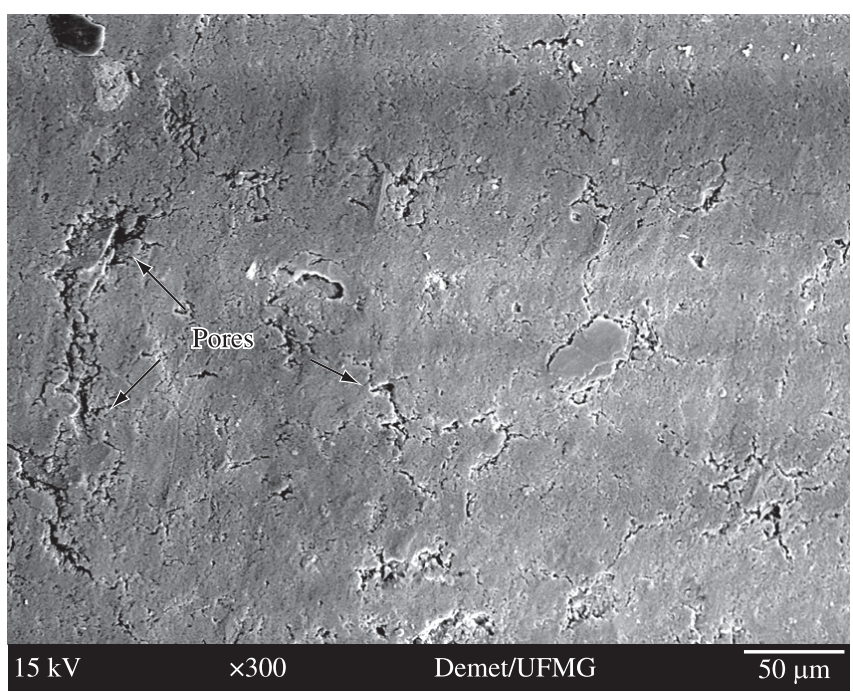

Figure 9. Composite $\mathrm{C} 4$, backscatter-mode scanning electron microscopy image. 


\section{Conclusion}

The addition of steatite in clay composites revealed promising effects on the mechanical properties. The pressure of compaction of $30 \mathrm{MPa}$ provided an increase of the linear shrinkage, the apparent density, the apparent porosity and the strength of the composites. The presence of magnesium oxide in the steatite increases the thermal shock resistance and diminishes the sintering shrinkage. The steatite particle size distribution of 100-200 US-Tyler affected the flexural strength providing a significant increase of the composite's strength when manufactured with 20 and $40 \%$ of steatite which was attributed to the crystalline phases formed, mainly cordierite. The steatite fraction of $20 \%$ exhibited superior results of density, porosity and mechanical strength. Finally, in this experiment, the clay based composite of superior properties is that one manufactured with $20 \%$ of steatite, 100-200 US-Tyler of particle size and $30 \mathrm{MPa}$ of compacting pressure.

\section{Acknowledgments}

The authors would like to express their gratitude to the financial support received by FAPEMIG under grant $n^{\circ}$. CEX 00221/06 and PIBIC.

\section{Reference}

1. Modesto C, Bristot V, Menegali G, Brida M, Mazzuco M, Mazon A et al. Obtenção e caracterização de materiais cerâmicos a partir de resíduos sólidos industriais. Cerâmica Industrial. 2003; 8:14-18.

2. Acchar W, Ramalho EG, Fonseca YA, Hotza D and Segadaes AM. Using granite rejects to aid densification and improve mechanical properties of alumina bodies. Jounal of Materials Science. 2005; 40:3905-3909.

3. Acchar W, Vieira FA and Segadaes AM. Using ornamental stone citting rejects as raw materials for red clay ceramic products: properties and microstructure development. Materials Science and Engineering. 2006; 606-610.

4. Menezes RR, Ferreira HS, Neves AG, Lira HL and Ferreira HC. Use of granite sawing wastes in the production of ceramic bricks and tiles. Journal of the European Ceramic Society. 2005; 25:1149-1158.

5. Monteiro SN, Pecanha LA and Vieira CMF. Reformulation of roofing tiles body with addition of granite waste from sawing operations. Journal of the European Ceramic Society. 2004; 24:2349-2356.

6. Yalcin N and Sevinc V. Utilization of bauxite waste in ceramic glazes. Ceramics International. 2000; 26:485-493.

7. Pereira FR, Hotza D, Segadaes AM and Labrincha JA. Ceramic formulations prepared with industrial wastes and natural sub-products. Ceramics International. 2006; 32:173-179.
8. Domingues EA and Ullman R. Ecological bricks made with clays and steel dust pollutants. Applied Clay Science. 1996; 11:237-249.

9. Malhotra SK and Dave NG. Investigations into the effect of addition of flyash and burnt clay pozzolana on certain engineering properties of cement composites. Cement and Concrete Composites. 1999; 21:285-291.

10. Monteiro SN, Silva FAN and Vieira CMF. Microstructural evaluation of a clay ceramic incorporated with petroleum waste. Applied Clay Science. 2006; 33:171-180.

11. Monteiro SN and Vieira CMF. Effect of oily waste addition to clay ceramic. Ceramics International. 2005; 31:353-358.

12. Rim KA, Ledhem A, Douzane $O$ and Dheilly Queneudec RMM. Influence of the proportion of wood on the thermal and mechanical performances of clay-cement-wood composites. Cement and Concrete Composites. 1999; 21:269-276.

13. Dondi M, Marsigli M and Fabbri B. Recycling of industrial and urban wastes in brick production: a review (Part 2). Tile \& Brick International. 1997; 13:302-309.

14. Mielcarek W, Wozny DN and Prociow K. Correlation between $\mathrm{MgSiO}_{3}$ phases and mechanical durability of steatite ceramics. Journal of the European Ceramic Society. 2004; 24:3817-3821.

15. White JS. Particle-size distribution of steatite talc. Journal of the American Ceramic Society. 1944; 27:320-323.

16. Amaral LF, Salomão R, Frollini E and Pandolfelli VC. Mechanisms of magnesium oxide hydration. Cerâmica. 2007; 53:368-372.

17. Werkema MCC and Aguiar S. Planejamento e análise de experimentos: como identificar e avaliar as principais variáveis influentes em um processo. Belo Horizonte: Fundação Christiano Ottoni, Escola de Engenharia da UFMG; 1996.

18. Montgomery DC. Introduction to statistical quality control. New York: John Wiley \& Sons; 1997.

19. ASTM. ASTM C326-03. Standard Test Method for Drying and Firing Shrinkages of Ceramic Whiteware Clays; 1996.

20. BRITISH STANDARD. BS 1881-114, Testing concrete, Methods for determination of density of hardened concrete; 1983.

21. BRITISH STANDARD. BS 10545-3, Determination of water absorption, apparent porosity, apparent relative density and bulk density; 1997.

22. BRITISH STANDARD. BS EN 658-3, Advanced technical ceramics. Mechanical properties of ceramic composites at room temperature, Determination of flexural strength. 2002.

23. BRITISH STANDARD. BS EN 12390-2, Testing hardened concrete, Making and curing specimens for strength tests. 2000.

24. Reed JS. Principles of ceramic processing. New York: John Wiley \& Sons; 1994

25. Bajza A. Structure of compacted cement pastes. Cement and Concrete Research. 1983; 13:239-245. 